\title{
Clinical assessment of efficacy of poly-L-lactide sternal pin on sternal stability and post-operative pain: a prospective randomized trial in cardiovascular surgery
}

\author{
Shingo Takahara ${ }^{1}$, Konosuke Sasaki ${ }^{1}$, Takeshi Saito ${ }^{1}$, Kei Sakuma ${ }^{1}$, Hidenori Fujiwara ${ }^{1}$, Ichiro Yoshioka $^{1}$, \\ Kiichiro Kumagai ${ }^{2}$, Wenyu Sun ${ }^{3}$, Kei Takase ${ }^{3}$, Yoshikatsu Saiki ${ }^{1,2}$ \\ ${ }^{1}$ Division of Cardiovascular Surgery, Tohoku University Graduate School of Medicine, Sendai, Japan; ${ }^{2}$ Research Division of Science for Aortic \\ diseases, Tohoku University Graduate School of Medicine, Sendai, Japan; ${ }^{3}$ Department of Diagnostic Radiology, Tohoku University Graduate School \\ of Medicine, Sendai, Japan \\ Contributions: (I) Conception and design: T Saito, K Kumagai, Y Saiki; (II) Administrative support: S Takahara, T Saito, K Kumagai, K Sasaki, Y \\ Saiki; (III) Provision of study materials or patients: S Takahara, T Saito, K Sakuma, H Fujiwara, I Yoshioka, K Kumagai, Y Saiki; (IV) Collection \\ and assembly of data: S Takahara, K Sasaki, W Sun, K Takase, Y Saiki; (V) Data analysis and interpretation: S Takahara, K Sasaki, Y Saiki; (VI) \\ Manuscript writing: All authors; (VII) Final approval of manuscript: All authors. \\ Correspondence to: Dr. Yoshikatsu Saiki, MD, PhD. 1-1 Seiryomachi, Aoba-ku, Sendai, Miyagi 980-8574, Japan. Email: yoshisaiki@med.tohoku.ac.jp.
}

Background: Although the incident rate is low, sternal dislocation and dehiscence due to unstable sternal fixation after cardiovascular surgery could cause potentially lethal complications. Thus, to enforce the stability of closed sternum, the sternal pins have been utilized at surgeon's discretion. However, there is no randomized clinical trial to test whether these pins are effective to stabilize a sternum. Hence, this study aimed to examine the clinical efficacy of bioabsorbable poly-L-lactide (PLLA) sternal pins in reinforcing sternal stability and preventing instability of the sternum after full sternotomy.

Methods: We conducted a single institutional, prospective, randomized, single-blinded clinical study involving 100 patients who underwent an initial cardiovascular surgery via sternotomy. Patients were randomly allocated into two groups: with (group P) and without (group N) PLLA sternal pins, at 1:1 ratio from November 2013 to April 2016. Sternal deviation and stability were assessed with postoperative computed tomography (CT) at two postures to put shear stress on the sternum. Additionally, information on patient demographic indices was obtained prospectively, and patient's pain intensity was assessed with numerical rating scoring system during rehabilitation. Furthermore, propensity score matching was performed for further comparative sub-analysis.

Results: Ninety-one patients (43 in group $\mathrm{P}$ and 48 in group $\mathrm{N}$ ) were analyzed using the intention-to-treat method. Group $\mathrm{N}$ had a significantly higher proportion of males $(\mathrm{P}=0.015)$ and ischemic disease as a primary diagnosis $(\mathrm{P}=0.040)$ than group $\mathrm{P}$. Postoperative CT showed that the degree of sternal deviation and stability were comparable between the groups. Similarly, the numerical rating score of pain during rehabilitation showed no difference between the groups. Even after adjusting for patient characteristics using propensity score matching method, no significant differences in sternal gaps, stability, and numerical rating score of pain were observed. Of note, no material-related adverse event such as wound infection was found.

Conclusions: We could not identify the efficacy of the sternal pin in enforcing sternal stability based on CT measurements with mild shear stress on sternum after cardiovascular surgery. Nevertheless, our results with no adverse events might encourage further investigations with a more specific cohort who is susceptible to infection but requires an additional sternal fixation.

Trial Registration: This study was registered in University Hospital Medical Information Network Clinical Trial Registry (UMIN000017357).

^ ORCID: 0000-0002-8363-293X. 
Keywords: Cardiovascular surgery; poly-L-lactide sternal pins (PLLA sternal pins); post-operative pain; randomized trial; sternal fixation

Submitted Aug 14, 2021. Accepted for publication Nov 08, 2021.

doi: $10.21037 /$ jtd-21-1340

View this article at: https://dx.doi.org/10.21037/jtd-21-1340

\section{Introduction}

Sternal dislocation and dehiscence after midline sternal incision are rare but could lead to devastating complications, such as mediastinitis (1-6). Moreover, unstable sternal fixation could cause postoperative pain, which impedes aggressive rehabilitation and consequently may lead to prolonged hospitalization. To prevent these sternal complications, stable and tight fixation of the sternum is vital (6-8).

Sternal closure with stainless-steel wires is the widely accepted standard procedure after median sternotomy. However, several biomechanical experiments suggested that stainless wire cerclage has insufficient stability, particularly under shear stress on the sternum (7,9-12); thus, various maneuvers have been developed to implement firm fixation of the sternum, including external and internal fixations (3,13-15).

Bioabsorbable sternal pins have been introduced in the field of cardiothoracic surgery and applied along with standard stainless wires to add the internal fixation at a surgeon's discretion $(16,17)$. Poly-L-lactide (PLLA) sternal pins (GRAND FIX Sternum Fixation; GUNZE Ltd., Tokyo, Japan) is designed to enhance internal fixation and achieve robust fixation stability to prevent the sternum from rubbing or separating. In fact, several retrospective clinical studies showed that the additive internal fixation using pins yields better stabilization than standard stainless wires $(17,18)$. Furthermore, our previous animal experiment demonstrated that a PLLA sternal pin enforces the sternum stiffness against anterior-posterior and cranial-caudal shear stress (9). However, no randomized prospective trial to test the efficacy of PLLA sternal pins in the clinical setting has been conducted.

Hence, we elected to conduct a randomized prospective clinical trial aimed to examine the efficacy of bioabsorbable PLLA sternal pins in enforcing sternal stability and preventing sternal dislocation under shear stress from upper limb mobilization as well as in mitigating pain during postoperative rehabilitation after full sternotomy.

We present the following article in accordance with the CONSORT reporting checklist (available at https://jtd. amegroups.com/article/view/10.21037/jtd-21-1340/rc).

\section{Methods}

\section{Subjects}

Adult patients ( $\geq 20$ and $<80$ years old) who were slated for an initial cardiovascular surgery with standard cardiopulmonary bypass through a median sternotomy were eligible for this study. Exclusion criteria included patients undergoing chronic hemodialysis and those who had received tranquilizers before enrollment. Moreover, patients whose chest left open, who underwent re-exploration for bleeding, and whose nociception could not be assessed due to significant morbidities, such as prolonged insertion of chest tubes and cerebral infarction, were also excluded from evaluation.

\section{Study design}

We conducted a randomized prospective clinical trial to examine the efficacy of bioabsorbable PLLA sternal pins in enforcing sternal stability and preventing sternal dislocation under shear stress. This single institutional, single-blinded, prospective, randomized study had two arms: with and without PLLA sternal pins (GRAND FIX Sternum Fixation, Figure $1 A$ ) at the time of sternal closure after a cardiovascular surgery through median sternotomy. The PLLA sternal pins were inserted according to the manufacture instruction. Briefly, at the end of a cardiovascular surgery, six single stainless wires, two on the manubrium and four on the sternal body, are put through the sternum. After that, two holes for the sternal pins were made on the marrow of sternum using the specific reamer and sizer (Figure 1B) between 1st and 2nd wires and between 4 th and 5 th wires. Subsequently, the sternal pins were inserted into the holes and the sternum was approximated and closed in the usual fashion. The patients were enrolled by surgeons, and written consents to participate in the clinical study were obtained from all patients. The enrolled patients were allocated into two groups at a ratio of $1: 1$ with 

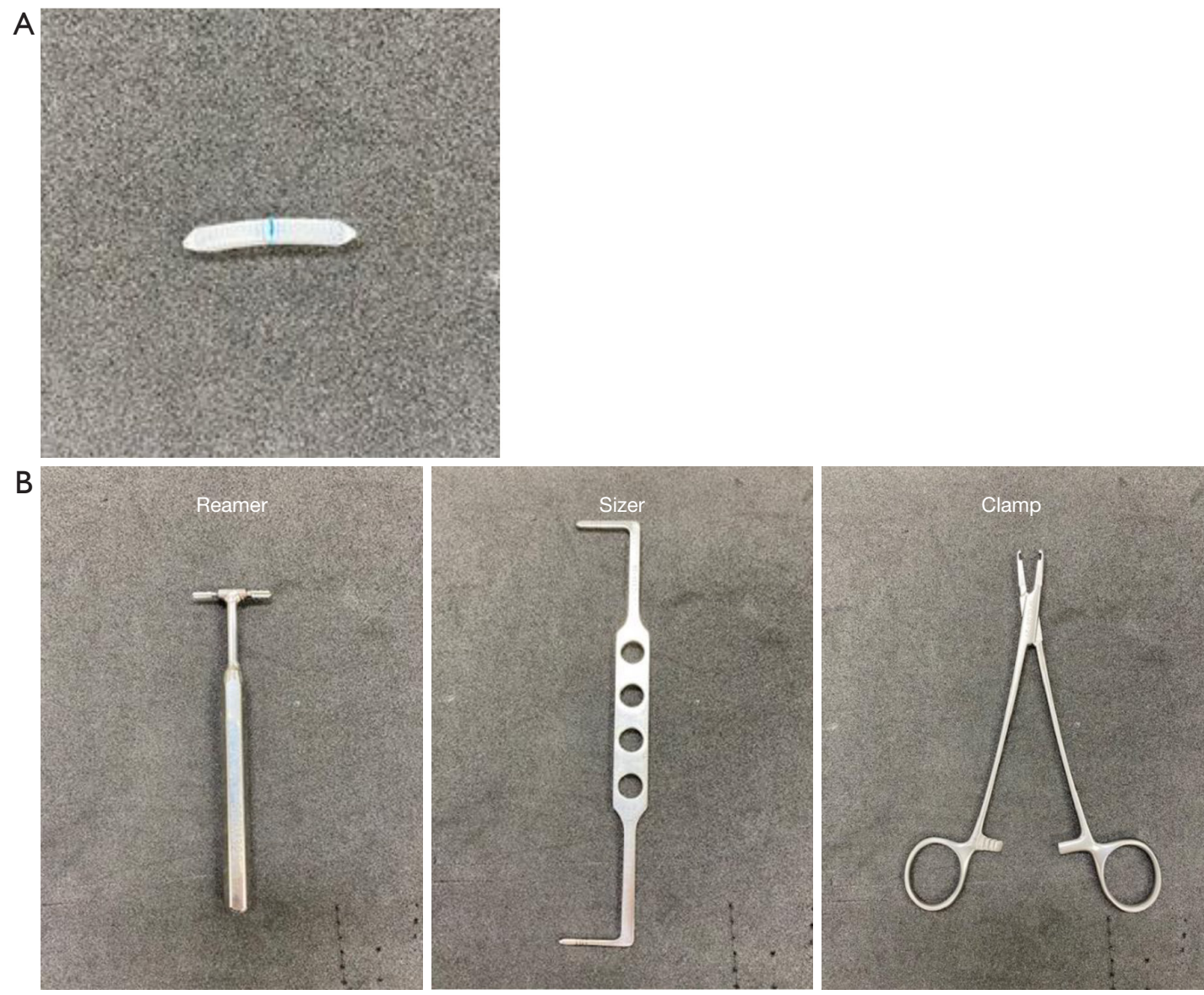

Figure 1 Poly-L-lactide sternal pin and tools required for implantation. (A) The appearance of poly-L-lactide sternal pin (GRAND FIX Sternum Fixation; GUNZE Ltd., Tokyo, Japan); (B) surgical instruments required to implant sternal pins, including the reamer and clamp to grab the pin. Images were provided by GUNZE Ltd. and the permission to publish was obtained.

sternal pins in addition to conventional stainless wires (group $\mathrm{P}, \mathrm{n}=50$ ) and with conventional stainless wires only (group $\mathrm{N}, \mathrm{n}=50$ ) using the following randomization method by a data manager. Firstly, the list of 100 slots with 50 of group $\mathrm{P}$ and 50 of group $\mathrm{N}$ was created. Then, the computergenerated random numbers were allocated to each slot. The list was sorted according to the assigned random numbers. Subsequently, the participants were assigned to each slot in order. The allocation sequence was generated by the data manager who was independent from clinical decisions and was concealed from evaluators, including radiologists, patients and physical therapists.

Sternal deviation was examined with computed tomography (CT) (1 mm thickness) approximately 3 weeks after surgery as we usually take a CT scan for patients who underwent a typical aortic surgery at this timing. CT was conducted with two different postures: right upper limb elevation and bilateral upper limbs elevation, in order to evaluate sternal gaps with multi-planar reconstruction using Aquarius Net Station (TeraRecon Inc., Foster City, CA, USA) by radiologists who were blinded to the patients' backgrounds and group. These two postures can generate different directions of shear stress on the sternum; the bilateral arms elevation yields rostral traction on both the divided sternums, whereas the right arm elevation induces rostral traction only on the right divided sternum. Anterior-posterior gap was defined as the maximal difference in the anterior surfaces between the right and left divided sternum; cranial-caudal gap, as the maximal difference at the top of the manubrium or body between the right and left divided sternum (Figure 2). Absolute values of differences in sternal gaps between the aforementioned two postures were calculated as an indicator of sternal stability since the direction of sternal 

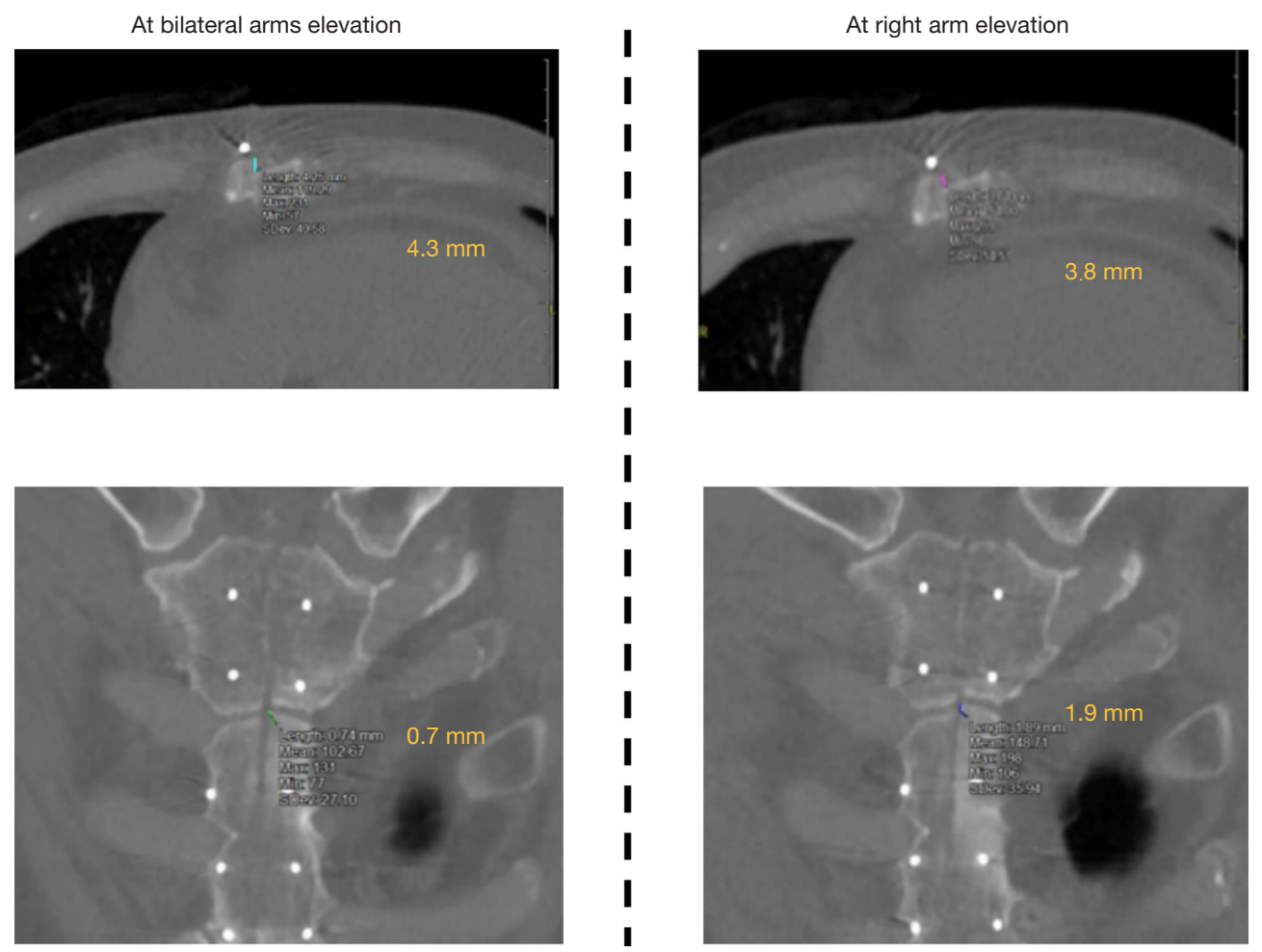

Figure 2 The representative computed-tomography images with assessment of sternal gaps at the two postures. The left images were taken with both arms elevated, while the right images were taken with only right arm elevated.

deviation, if exists, should differ among patients. All clinical information was procured prospectively. Pain on the chest was evaluated by a physical therapist after 10-14 days from the index operation. The level of pain was assessed at three postures, including bed rest, right upper limb elevation, and sit up position (Figure 3), and expressed according to numerical rating scale (NRS), where 0 means no pain, 1-3 means mild pain [nagging, annoying, slightly interfering with activities of daily living (ADLs)], 4-6 means moderate pain (significantly interferes with ADLs), and 7-10 means severe pain (disabling or unable to perform ADLs) (19).

The trial was conducted in accordance with the Declaration of Helsinki (as revised in 2013). The study was approved by the Ethics Committee of Tohoku University Graduate School of Medicine (2013-2-097). This clinical trial, which was conducted from November 2013 to April 2016, was registered in University Hospital Medical Information Network Clinical Trial Registry (UMIN000017357), and written informed consent was taken from all individual participants. The enrollment was ended when the number of applicants achieved 100 .

\section{Propensity score matching}

A logistic regression model with sternal pin as the dependent variable was employed for the baseline characteristics, with sex and primary diagnosis as covariates. One-to-one pair matching, a nearest neighbor algorithm, and a caliper of 0.20 were used for the matching process. Subsequently, covariate balance between the matched subgroups was ensured. A total of 32 patients were selected in each subgroup.

\section{Statistical analysis}

The sample size was determined based on the data from a previous report (20). Briefly, given that the sternal dislocation, defined as gaps between cut sternums in more than half of the sternum depth (the average depth of sternum is reported to be around $30 \mathrm{~mm}$ ) will happen in $20 \%$ patients with the standard wire closure as reported (20) as well as given that sternal pins will negate this dislocation, the calculated required sample size was 40:40 (total 80), with $80 \%$ power and $5 \%$ type I error level. The probability 

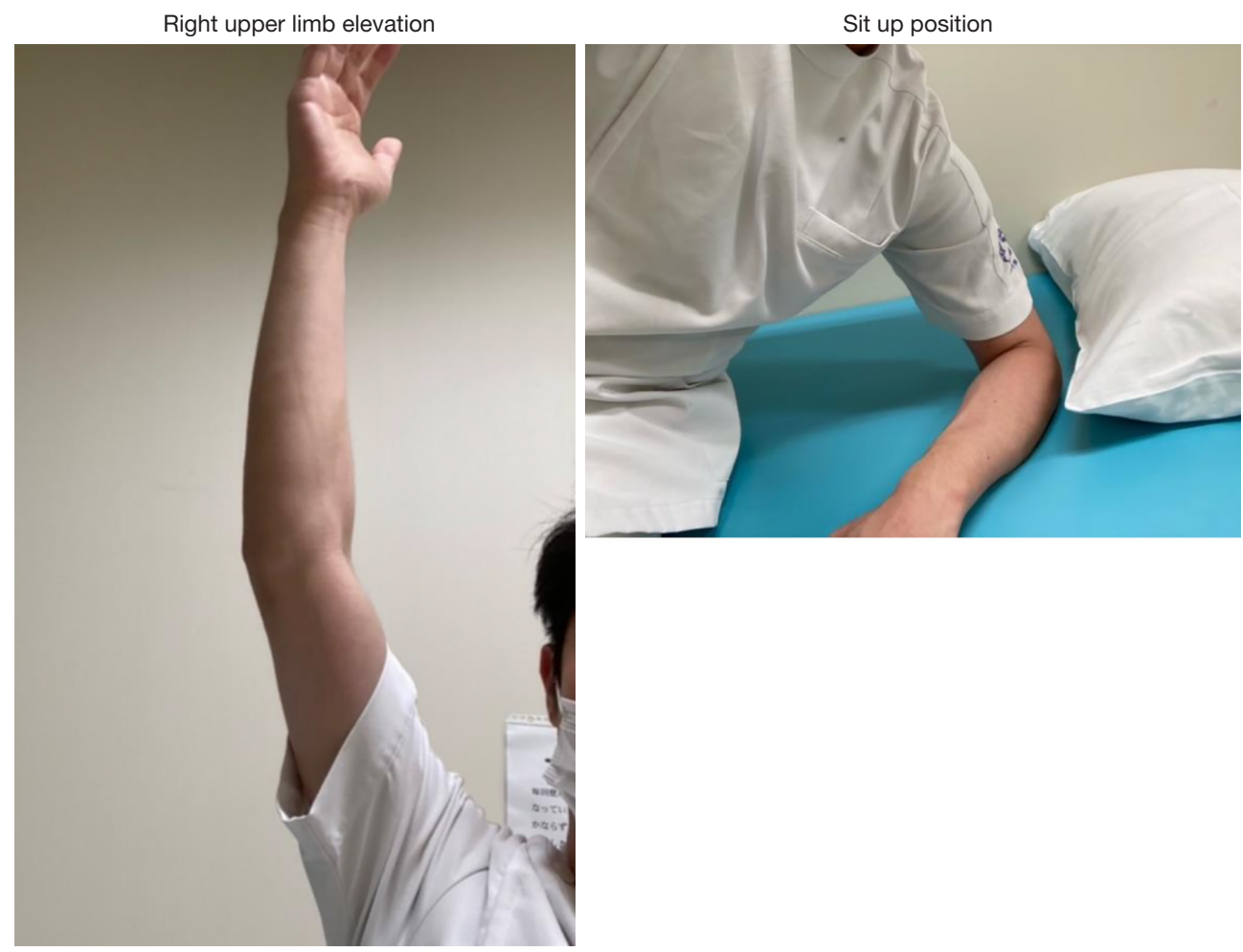

Figure 3 The postures for nociception assessment. The postoperative pain was evaluated at three postures, including bed rest, right arm elevation (left), and sit up position (right).

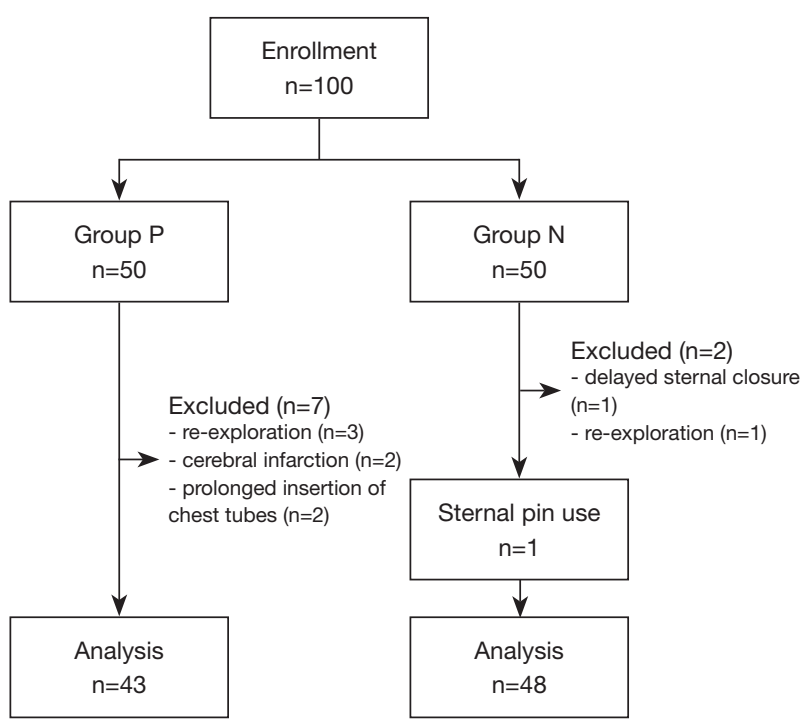

Figure 4 Study enrollment. In group P, we excluded the patients with cerebral infarction $(n=2)$ and prolonged insertion of chest tubes $(n=2)$ with a concern for inappropriate assessment of nociception. of differences between two groups was determined by Student's $t$-test or Mann-Whitney U test for numerical data and by chi-square test for categorical data. Comparisons between three or more groups were performed using oneway ANOVA or Kruskal-Wallis. Simple and multiple regression analyses were performed to determine the contribution of sternal pins and other variables to the sternal gaps and instability. A P value $<0.05$ was considered statistically significant. Statistical analyses were performed by JMP Pro 15.2.0 (SAS, Cary, NC, USA) for regression analysis and SPSS version 24 (IBM Corp., Chicago, IL, USA) for the rest.

\section{Results}

\section{Patient characteristics}

As shown in Figure 4, 43 patients in group $\mathrm{P}$ and 48 patients in group $\mathrm{N}$ were analyzed after excluding ineligible patients. 
Table 1 Patient characteristics

\begin{tabular}{|c|c|c|c|}
\hline Variables & Group P $(n=43)$ & Group N (n=48) & $P$ value \\
\hline Mean \pm SD & $62.5 \pm 13.0$ & $63.2 \pm 10.0$ & 0.208 \\
\hline Median (IQR) & $67.0(57.0-70.0)$ & 65.5 (59.0-71.0) & 0.965 \\
\hline Male, n (\%) & $26(60.4)$ & $40(83.3)$ & $0.015^{\star}$ \\
\hline Mean \pm SD & $23.3 \pm 3.3$ & $24.1 \pm 3.0$ & \\
\hline Median (IQR) & 22.8 (16.8-25.9) & $24.1(21.8-26.3)$ & \\
\hline $\operatorname{BSA}\left(m^{2}\right)$ & & & $0.016^{\star}$ \\
\hline Mean \pm SD & $1.61 \pm 0.18$ & $1.70 \pm 0.16$ & \\
\hline Hypertension, n (\%) & $23(53.5)$ & $24(50.0)$ & 0.740 \\
\hline Dyslipidemia, n (\%) & $12(27.9)$ & $16(33.3)$ & 0.576 \\
\hline Diabetes mellitus, n (\%) & 7 (16.3) & $16(33.3)$ & 0.062 \\
\hline \multicolumn{4}{|l|}{ Primary diagnosis, $\mathrm{n}(\%)$} \\
\hline Valvular & $28(65.1)$ & $23(47.9)$ & 0.099 \\
\hline Ischemic & $5(11.6)$ & $14(29.2)$ & $0.040^{*}$ \\
\hline Aortic & $11(25.6)$ & $9(18.8)$ & 0.432 \\
\hline Others & $2(4.7)$ & $4(8.3)$ & 0.480 \\
\hline
\end{tabular}

$\mathrm{P}$ values were derived by Student's $t$-test or Mann-Whitney $\mathrm{U}$ test or chi-square test, as appropriate. * $\mathrm{P}<0.05$. BMI, body mass index; BSA, body surface area.

Sternal pins were inserted in one patient in group $\mathrm{N}$ based on the surgeon's discretion; the patient was included in group $\mathrm{N}$ as part of an intention-to-treat population (Figure 4).

Patient characteristics are summarized in Table 1. Group $\mathrm{N}$ had a significantly larger proportion of males, resulting in a larger body surface area (BSA), and ischemic disease as the primary diagnosis than group $\mathrm{P}$, although other parameters, including hypertension, dyslipidemia, and diabetes mellitus, were evenly distributed (Table 1).

\section{Outcomes for primary endpoint}

Postoperative CT revealed that sternal deviation was not different between groups $\mathrm{P}$ and $\mathrm{N}$ in both two postures (Table 2). Also, no inter-group differences in the magnitude of changes in sternal gaps according to postural changes were found. Moreover, no difference in NRS of pain between the two groups was observed at any of the three postures during post-operative rehabilitation (Table 2).

\section{The effects of uneven factors}

To investigate whether the uneven factors between the two groups that we encountered in the patients' background, such as sex, BSA and the primary diagnosis, affected the outcomes or not, the correlations between those factors and sternal gaps/stability as well as NRS were analyzed. We found that any factors that were distributed unevenly did not have a significant correlation with the outcomes (Tables 3-5).

\section{Regression analysis for the effects of sternal pin and variables to sternal gaps and stability}

To further examine the effects of sternal pin as well as other variables on the sternal gaps and instability, we performed the simple and multiple regression analyses. To simplify, we 
Table 2 Outcomes of sternal stability and pain assessment in the two groups

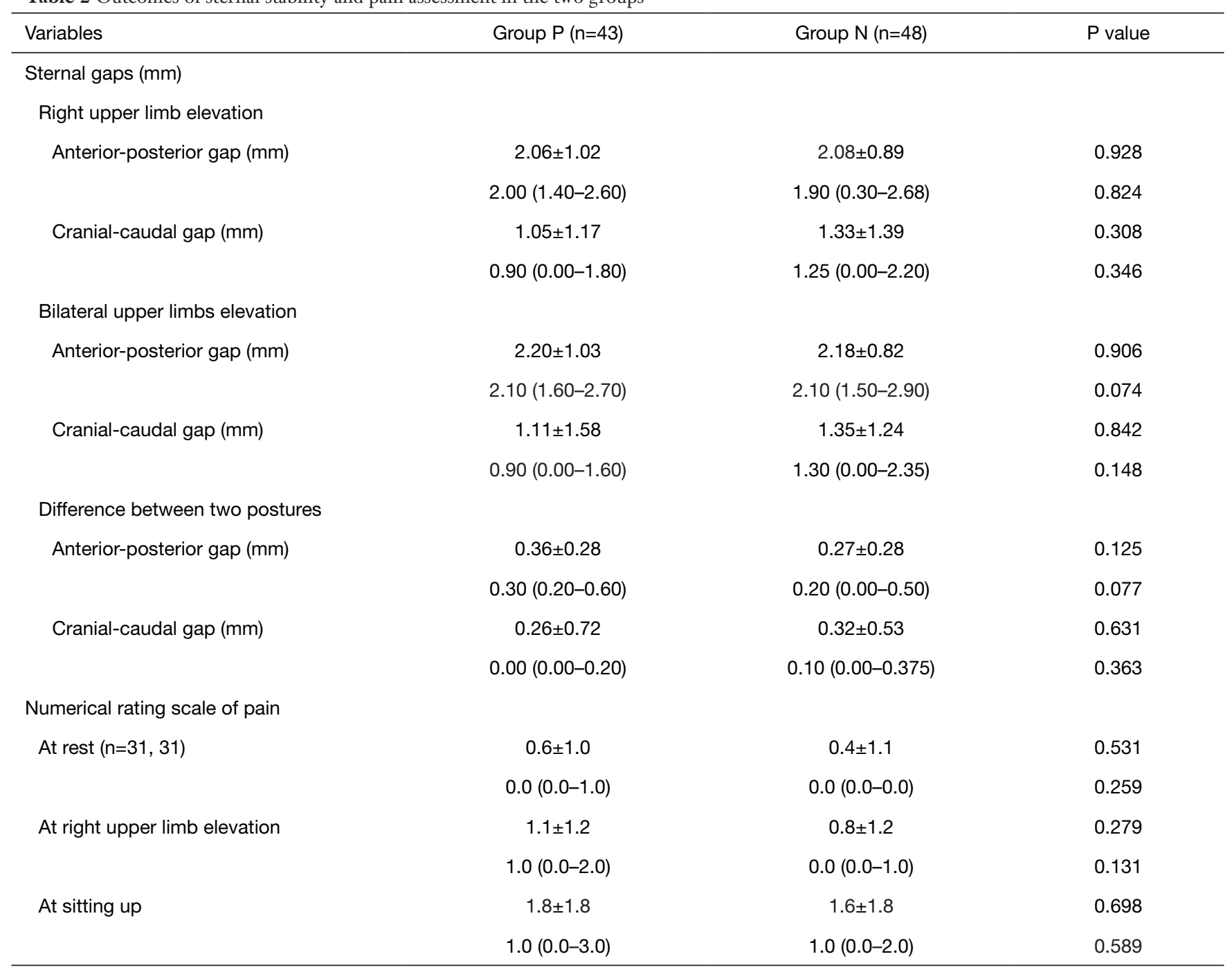

Data are presented as mean \pm SD and median (IQR). P values were derived by Student's $t$-test and Mann-Whitney $U$ test.

set the maximal gap, either antero-lateral or cranial-caudal direction, and stability as outcomes. As the result, we found that there is no significant effect on sternal gaps/stability by either the existence of sternal pin or other variables, including age, sex, BSA and primary diagnosis (Tables 6,7).

\section{Clinical course}

No mortality and no wound infection, such as mediastinitis, was observed even in the excluded patients. Clinical courses of subjected patients were comparable between groups, including the duration of intensive care unit stay $(5.2 \pm 3.1$ and 5.3 \pm 2.9 days in groups $\mathrm{P}$ and $\mathrm{N}$, respectively; $\mathrm{P}=0.919$ ) and the period to drain removal $(6.3 \pm 3.4$ and $5.6 \pm 2.2$ days in groups $\mathrm{P}$ and $\mathrm{N}$, respectively; $\mathrm{P}=0.254$ ).

\section{Assessment after propensity score matching}

Since the even distribution of patients' background failed to some extent, propensity score matching analysis was performed with procured data to obtain more reliable results. Using a 1:1 propensity score matching, we generated a subpopulation with two groups (32 patients in each group), with adjustment for sex and primary diagnosis.

As shown in Table 8, the distribution of all baseline patient characteristics was balanced and the outcomes were compared between the two subgroups. The gaps in both anterior-posterior and cranial-caudal directions were still 
Table 3 Difference in sternal deviations/stability between sexes in all participants

\begin{tabular}{|c|c|c|c|}
\hline Variables & Male $(n=66)$ & Female $(n=25)$ & $P$ value \\
\hline \multicolumn{4}{|l|}{ Right upper limb elevation } \\
\hline \multirow[t]{2}{*}{ Anterior-posterior gap (mm) } & $2.02 \pm 1.00$ & $2.21 \pm 0.82$ & 0.398 \\
\hline & $1.80(1.40-2.63)$ & $2.20(1.50-2.60)$ & 0.322 \\
\hline Cranial-caudal gap (mm) & $1.00(0.00-2.13)$ & $1.00(0.00-1.65)$ & 0.699 \\
\hline \multicolumn{4}{|l|}{ Bilateral upper limbs elevation } \\
\hline \multirow[t]{2}{*}{ Anterior-posterior gap (mm) } & $2.13 \pm 0.95$ & $2.34 \pm 0.81$ & 0.333 \\
\hline & $2.05(1.50-2.53)$ & $2.30(1.80-2.90)$ & 0.182 \\
\hline \multicolumn{4}{|l|}{ Difference between two postures } \\
\hline \multirow[t]{2}{*}{ Anterior-posterior gap (mm) } & $0.32 \pm 0.28$ & $0.30 \pm 0.27$ & 0.733 \\
\hline & $0.30(0.10-0.50)$ & $0.20(0.10-0.50)$ & 0.723 \\
\hline \multirow[t]{2}{*}{ Cranial-caudal gap (mm) } & $0.34 \pm 0.71$ & $0.15 \pm 0.27$ & 0.210 \\
\hline & $0.05(0.00-0.40)$ & $0.07(0.00-0.20)$ & 0.550 \\
\hline \multicolumn{4}{|l|}{ Numerical rating scale of pain } \\
\hline \multirow[t]{2}{*}{ At rest $(n=43,19)$} & $0.5 \pm 1.1$ & $0.5 \pm 0.8$ & 0.976 \\
\hline & $0.0(0.0-0.0)$ & $0.0(0.0-1.0)$ & 0.332 \\
\hline
\end{tabular}

Data are presented as mean \pm SD and median (IQR). P values were derived by Student's $t$-test and Mann-Whitney $U$ test.

comparable between the matched groups (groups $\mathrm{P}$ and $\mathrm{N}$; Table 9). Moreover, differences in the corresponding gaps between the two postures were also comparable between the subgroups. Regarding pain assessment, no differences in the magnitude of pain at any of the three postures between the two groups were noted even after matching (Table 9).

\section{Discussion}

With the prospective, randomized clinical study, we investigated the efficacy of PLLA sternal pins used in the combination with conventional stainless wires to achieve more stable fixation of the divided sternum. We assessed motion deviation in addition to static misalignment based on early post-operative CT with multi-planar reconstruction as well as possible modification of nociception as a clinical manifestation of sternal instability. Against our hypothesis where the additional sternal pins would provide more stable fixation leading to less misalignment of the sternum, we found no significant mitigation of static misalignment and motion deviation along with the magnitude of motion pain in patients with additive PLLA pins in comparison to those without sternal pins. However, the present study was found to bear one obvious limitation, the uneven distribution of patients' background factors, possibly due to the small sample size in each group. Thus, we subsequently examined possible confounding bias by analyzing the correlations between unevenly distributed factors, such as sex, BSA and 
Table 4 Difference in sternal deviations/stability between the primary diagnoses in all participants

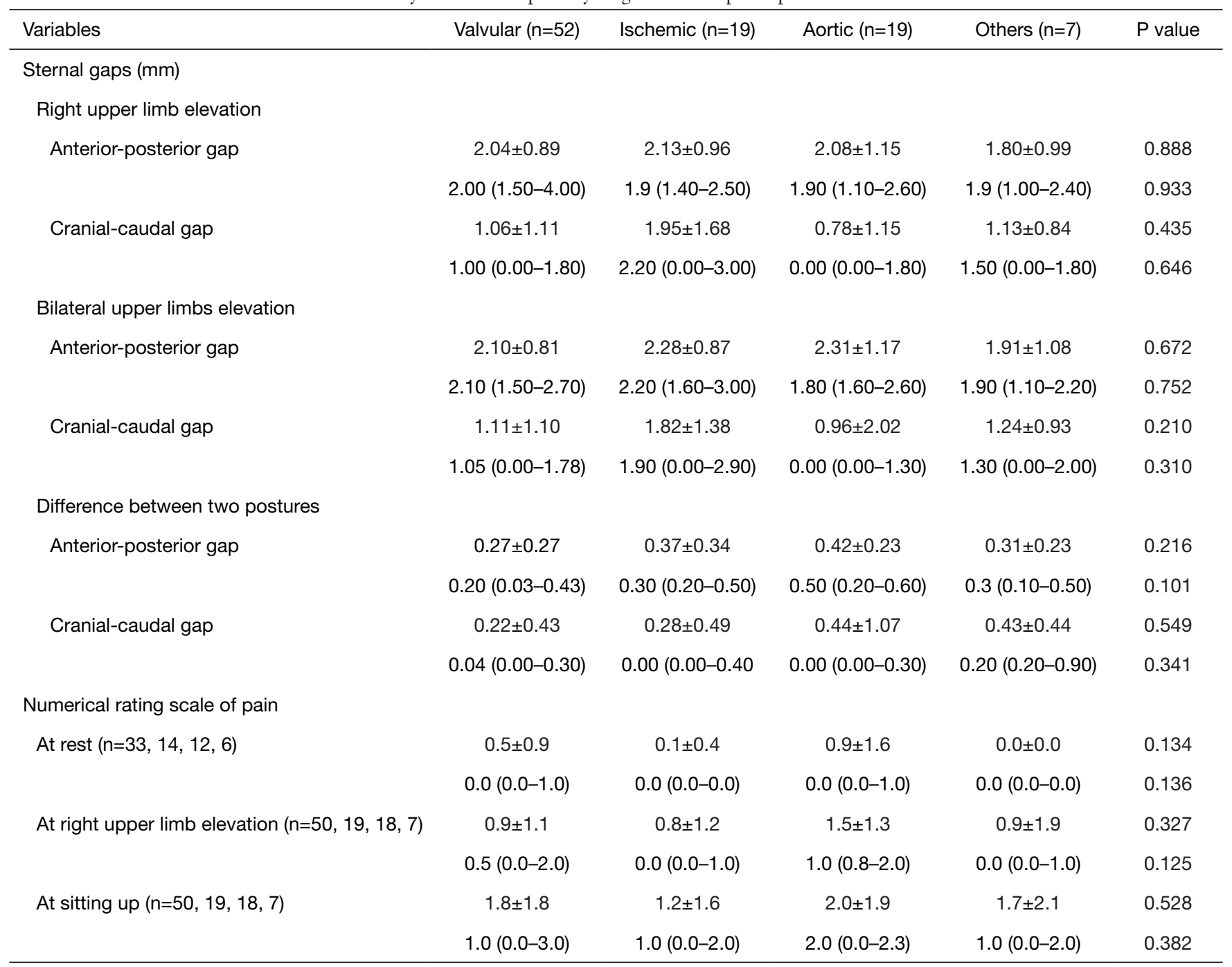

Data are presented as mean \pm SD and median (IQR). P values were derived by one-way ANOVA or Kruskal-Wallis test.

the primary diagnosis and pre-determined endpoints. We, then, found that it is unlikely that those factors affected the outcomes, including sternal gaps/stability and NRS. We further confirmed these findings with matching unevenly distributed factors using the propensity score matching technique.

Previously, we demonstrated that PLLA sternal pins could increase sternal stability particularly under shear stress on the sternum in biomechanical experiments using an extirpated sternum from juvenile swine (9). Koshiyama et al. also biomechanically showed the efficacy of hydroxyapatite/ PLLA using an artificial sternum (21). Nevertheless, we could not identify the efficacy of the sternal pins in this study. Of note, the sternal misalignments and pain at the evaluations without sternal pins were already negligible in the present cohort. Thus, the room for the additive PLLA pins to improve sternal stability and to relieve pain was extremely limited. Furthermore, the previous mechanistic studies showed that the external force required to make a $1 \mathrm{~mm}$ deviation in the steel wire-fixed artificial sternum was over $50 \mathrm{~N}$ (approximately $5.1 \mathrm{kgf}$ ) in the anteriorposterior direction and over $80 \mathrm{~N}$ (approximately $8.2 \mathrm{kgf}$ ) in the cranial-caudal direction $(9,10)$. However, human upper limb weight is supposed to be approximately $5.0 \%$ of the body weight (22), which corresponds to only $3.5 \mathrm{~kg}$ in a patient weighing $70 \mathrm{~kg}$. Thus, even though we attempted to add some shear stress on the sternum with a careful consideration of potential risks unlike a previous clinical 
Table 5 Correlation between BSA and sternal deviations/stability in all participants

\begin{tabular}{|c|c|c|}
\hline Variables & Pearson's $r$ & $P$ value \\
\hline \multicolumn{3}{|l|}{ Right upper limb elevation } \\
\hline Anterior-posterior gap & 0.099 & 0.866 \\
\hline Cranial-caudal gap & 0.259 & 0.744 \\
\hline \multicolumn{3}{|l|}{ Bilateral upper limbs elevation } \\
\hline Anterior-posterior gap & -0.359 & 0.522 \\
\hline Cranial-caudal gap & -0.040 & 0.963 \\
\hline \multicolumn{3}{|l|}{ Difference between two postures } \\
\hline Anterior-posterior gap & -0.037 & 0.829 \\
\hline At rest $(n=62)$ & -0.297 & 0.692 \\
\hline At right upper limb elevation $(n=88)$ & -0.410 & 0.589 \\
\hline At sitting up $(\mathrm{n}=88)$ & -0.396 & 0.719 \\
\hline
\end{tabular}

The $r$ and $P$ values were derived with the Pearson's linear regression model. BSA, body surface area.

Table 6 Regression analysis results for maximal gaps

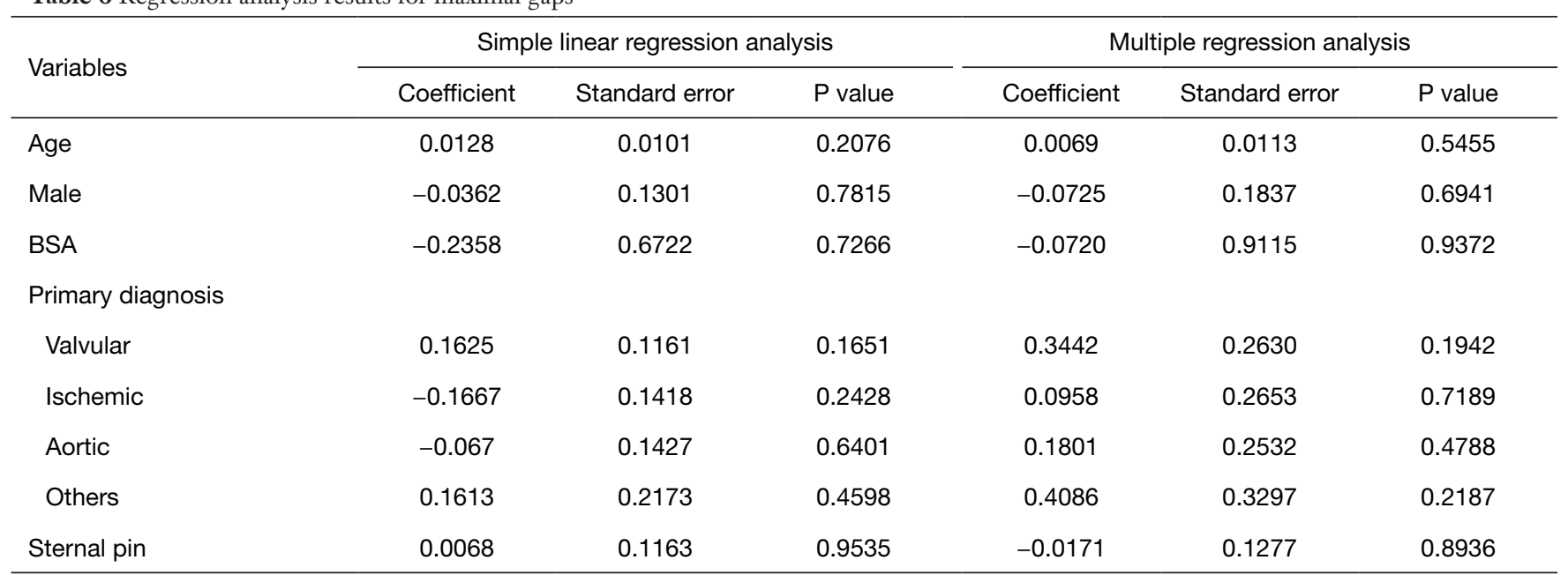

$\mathrm{R}$ square for multiple regression analysis $=0.0576$. BSA, body surface area.

trial (16), the lack of beneficial effect of PLLA pins as an additive internal fixation in the present study is likely due to the insufficient shear stress on the sternum, which is one of the limitations of this study. Nevertheless, when considering the realistic clinical condition during the early postoperative period, it might be suboptimal to put shear stress on the sternum with a magnitude as high as that employed in the aforementioned biomechanical experiments. In fact, even with relatively aggressive guidelines for rehabilitation, mobilization and resistance training during the postoperative phase are restricted during 4-6 weeks after cardiac surgery, such as coronary artery bypass grafting, for safety and efficacy (23). Furthermore, in this study, we did not include some high-risk patient cohorts, such as 
Table 7 Regression analysis results for sternal instability

\begin{tabular}{|c|c|c|c|c|c|c|}
\hline Variables & \multicolumn{3}{|c|}{ Simple linear regression analysis } & \multicolumn{3}{|c|}{ Multiple regression analysis } \\
\hline Age & 0.0077 & 0.0055 & 0.1661 & 0.0067 & 0.0061 & 0.2731 \\
\hline Male & 0.0915 & 0.0707 & 0.1989 & 0.1680 & 0.0987 & 0.0925 \\
\hline BSA & -0.0616 & 0.3687 & 0.8677 & -0.5709 & 0.4900 & 0.2469 \\
\hline Valvular & 0.1128 & 0.0632 & 0.0778 & 0.0508 & 0.1412 & 0.7201 \\
\hline Ischemic & -0.0453 & 0.0782 & 0.5637 & -0.0886 & 0.1425 & 0.9526 \\
\hline Aortic & -0.1451 & 0.0768 & 0.0622 & -0.0886 & 0.1360 & 0.5165 \\
\hline Others & 0.006 & 0.1195 & 0.9604 & -0.0658 & 0.1771 & 0.7110 \\
\hline
\end{tabular}

$R$ square for multiple regression analysis $=0.0954$. BSA, body surface area.

Table 8 Patient characteristics after propensity score matching

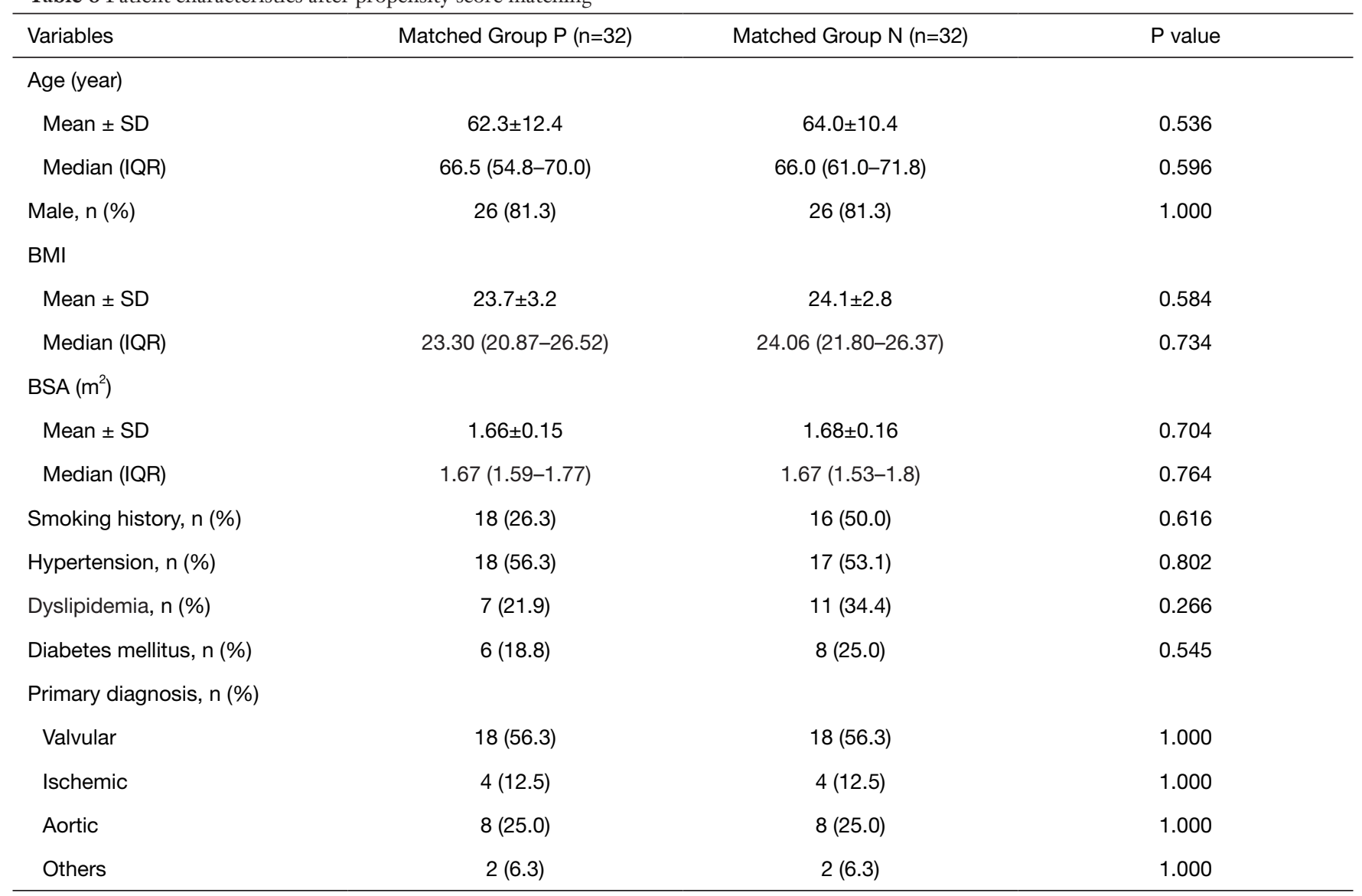

$\mathrm{P}$ values were derived by Student's $t$-test or Mann-Whitney $U$ test or chi-square test, as appropriate. BMI, body mass index; BSA, body surface area. 
Table 9 Outcome after propensity score matching

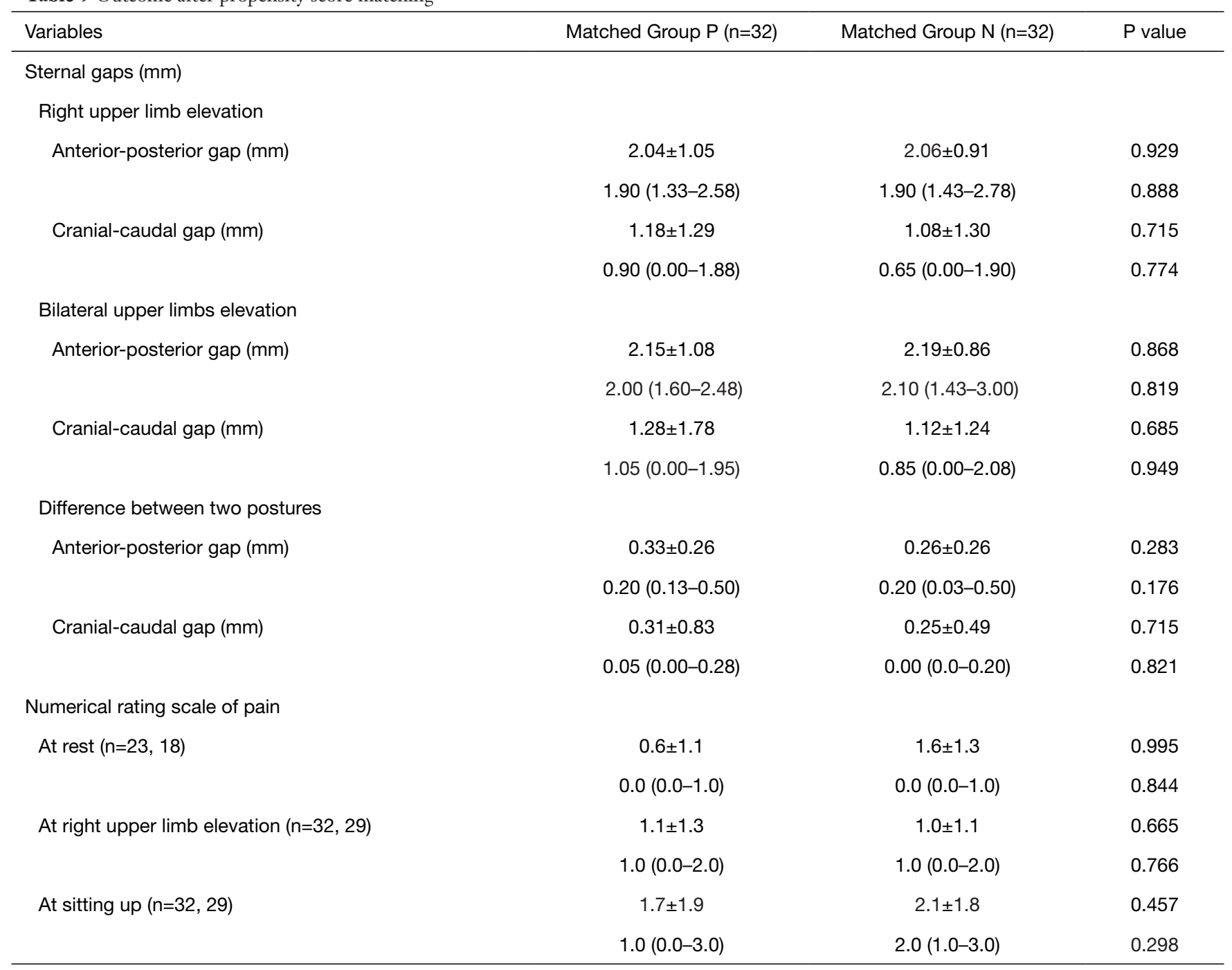

Data are presented as mean \pm SD and median (IQR). P values were derived by Student's $t$-test and Mann-Whitney $U$ test.

elder patients and patients who require chronic dialysis, which are known as risk factors of sternal complications $(24,25)$. Although our exclusion criteria had been set in consideration of the risk where artificial material could increase infection rate in these susceptible patients to infection, this also could be a reason by which we did not observe any beneficial effect by the sternal pins.

As such, in consideration of clinically practical usage of PLLA pins, there is a tenacious concern that the artificial material could potentially increase the chances of infection. Of importance, in this study, no artificial material-related adverse events, such as wound infection, were found, which is consistent with several previous studies $(3,16,20)$.
What makes this PLLA pins unique from other rigid sternal fixations is that the PLLA is bioabsorbable. In fact, the strength of the sternal pin drops relatively fast in 4-6 months due to degradation by hydrolysis, although the molecules itself remains until a couple of years later (26); thus, there is little long-term concern about infection on the material. This feature and our findings would encourage us to explore the efficacy of the sternal pins in a patient who is susceptive to infection but requires an extra-fixation due to friable sternum, which is likely to contribute to sternal misalignment and/or nonunion $(25,27)$.

This study has some limitations, including the intrinsic limitations derived from a single institutional study and 
the small sample size. Another limitation is that despite the small sample size targeted, the present study required a relatively long period, approximately 2.5 years, to enroll 100 patients since there were some other simultaneously running clinical studies and some eligible patients opted not to be enrolled. Furthermore, the differences in sternal gaps were evaluated between the two postures, i.e., right upper limb elevation and bilateral upper limbs elevation, as the indices for sternal instability; however, the measurements of sternal gaps in a natural posture with bilateral limbs down were not performed in view of minimizing radiation exposure to our study patients for this specific research protocol. Moreover, although we did not measure the sternal dehiscence between cut sternums as the sternal pin is deemed not to have any support in inward direction, the sternal dehiscence is an important factor leading to the sternal complication. Such additional measurements might have provided us with some different data.

\section{Conclusions}

In this study, no significant difference in sternal stability and in pain during the early phase of post-cardiovascular surgery between patients with and without sternal pins was observed. Nevertheless, since no material-related morbidity was observed, our result might encourage to examine the efficacy of this sternal fixation method in patients with a higher risk of sternal complications. Additionally, further clinical studies with longer term observation and more aggressive shear stress on the sternum corresponding to the daily activities are needed.

\section{Acknowledgments}

We wish to express our appreciation to Marina Suzuki for providing assistance in this clinical study as well as Masashi Takeuchi for assessing the pain during rehabilitation for this study and providing photographs depicting the position where the pain was evaluated (Figure 3).

Funding: None.

\section{Footnote}

Reporting Checklist: The authors have completed the CONSORT reporting checklist. Available at https://jtd. amegroups.com/article/view/10.21037/jtd-21-1340/rc

Trial Protocol: Available at https://jtd.amegroups.com/ article/view/10.21037/jtd-21-1340/tp

Data Sharing Statement: Available at https://jtd.amegroups. com/article/view/10.21037/jtd-21-1340/dss

Peer Review File: Available at https://jtd.amegroups.com/ article/view/10.21037/jtd-21-1340/prf

Conflicts of Interest: All authors have completed the ICMJE uniform disclosure form (available at https://jtd. amegroups.com/article/view/10.21037/jtd-21-1340/coif). The remuneration for KK is derived from the budget for the Research Division of Sciences for Aortic Disease, which is partially supported by GUNZE Ltd. YS is in charge of running the Research Division of Sciences for Aortic Disease. The other authors have no conflict of interest.

Etbical Statement: The authors are accountable for all aspects of the work in ensuring that questions related to the accuracy or integrity of any part of the work are appropriately investigated and resolved. The trial was conducted in accordance with the Declaration of Helsinki (as revised in 2013). The study was approved by the Ethics Committee of Tohoku University Graduate School of Medicine (2013-2-097). This clinical trial, which was conducted from November 2013 to April 2016, was registered in University Hospital Medical Information Network Clinical Trial Registry (UMIN000017357), and written informed consent was taken from all individual participants.

Open Access Statement: This is an Open Access article distributed in accordance with the Creative Commons Attribution-NonCommercial-NoDerivs 4.0 International License (CC BY-NC-ND 4.0), which permits the noncommercial replication and distribution of the article with the strict proviso that no changes or edits are made and the original work is properly cited (including links to both the formal publication through the relevant DOI and the license). See: https://creativecommons.org/licenses/by-nc-nd/4.0/.

\section{References}

1. Goldman G, Nestel R, Snir E, et al. Effective technique of sternum closure in high-risk patients. Arch Surg 1988;123:386-7.

2. Song DH, Lohman RF, Renucci JD, et al. Primary sternal plating in high-risk patients prevents mediastinitis. Eur J 
Cardiothorac Surg 2004;26:367-72.

3. Tanaka T, Okawa Y, Ishida N, et al. Clinical studies of bioabsorbable poly-L-lactide sternal coaptation pins. J Cardiovasc Surg (Torino) 2001;42:749-51.

4. Oiwa H, Ishida R, Sudo K. Sternal closure with reabsorbable pin and cord in pediatric-less invasive cardiac surgery. Ann Thorac Surg 2004;78:358-9.

5. Hamaji M, Sakaguchi Y, Matsuda M, et al. Reinforced closure of the sternum with absorbable pins for high-risk patients. Interact Cardiovasc Thorac Surg 2009;9:559-61.

6. Robicsek F, Fokin A, Cook J, et al. Sternal instability after midline sternotomy. Thorac Cardiovasc Surg 2000;48:1-8.

7. Cohen DJ, Griffin LV. A biomechanical comparison of three sternotomy closure techniques. Ann Thorac Surg 2002;73:563-8.

8. Schimmer C, Reents W, Berneder S, et al. Prevention of sternal dehiscence and infection in high-risk patients: a prospective randomized multicenter trial. Ann Thorac Surg 2008;86:1897-904.

9. Saito T, Iguchi A, Sakurai M, et al. Biomechanical study of a poly-L-lactide (PLLA) sternal pin in sternal closure after cardiothoracic surgery. Ann Thorac Surg 2004;77:684-7.

10. Pai S, Gunja NJ, Dupak EL, et al. In vitro comparison of wire and plate fixation for midline sternotomies. Ann Thorac Surg 2005;80:962-8.

11. McGregor WE, Trumble DR, Magovern JA. Mechanical analysis of midline sternotomy wound closure. J Thorac Cardiovasc Surg 1999;117:1144-50.

12. Losanoff JE, Collier AD, Wagner-Mann CC, et al. Biomechanical comparison of median sternotomy closures. Ann Thorac Surg 2004;77:203-9.

13. Raman J, Song DH, Bolotin G, et al. Sternal closure with titanium plate fixation--a paradigm shift in preventing mediastinitis. Interact Cardiovasc Thorac Surg 2006;5:336-9.

14. Okutan H, Tenekeci C, Kutsal A. The reinforced sternal closure system is reliable to use in elderly patients. J Card Surg 2005;20:271-3.

15. Allen KB, Thourani VH, Naka Y, et al. Randomized, multicenter trial comparing sternotomy closure with rigid plate fixation to wire cerclage. J Thorac Cardiovasc Surg 2017;153:888-896.e1.

16. Fu XM, Oshima H, Araki Y, et al. A comparative study of two types of sternal pins used for sternal closure: poly-L-lactide sternal pins versus uncalcined hydroxyapatite poly-L-lactide sternal pins. J Artif Organs 2013;16:458-63.

17. Kawamura M, Masai T, Matsue H, et al. Analysis of the sternum for sternal closure with bioabsorbable sternal pins. Asian Cardiovasc Thorac Ann 2013;21:331-4.

18. Ito T, Kudo M, Yozu R. Usefulness of osteosynthesis device made of hydroxyapatite-poly-L-lactide composites in port-access cardiac surgery. Ann Thorac Surg 2008;86:1905-8.

19. Dworkin RH, Turk DC, Farrar JT, et al. Core outcome measures for chronic pain clinical trials: IMMPACT recommendations. Pain 2005;113:9-19.

20. Tsunekawa T, Usui A, Oshima H, et al. A bioresorbable osteosynthesis device can induce an earlier sternal fusion after median sternotomy. Interact Cardiovasc Thorac Surg 2012;15:377-81.

21. Koshiyama H, Yamazaki K. Absorbable sternal pins improve sternal closure stability within a small deviation. Gen Thorac Cardiovasc Surg 2015;63:331-4.

22. de Leva P. Adjustments to Zatsiorsky-Seluyanov's segment inertia parameters. J Biomech 1996;29:1223-30.

23. Adams J, Cline MJ, Hubbard M, et al. A new paradigm for post-cardiac event resistance exercise guidelines. Am J Cardiol 2006;97:281-6.

24. Osawa H, Yoshii S, Abraham SJ, et al. Topical spraying of cefazolin and gentamicin reduces deep sternal wound infections after heart surgery: a multicenter, large volume, retrospective study. Gen Thorac Cardiovasc Surg 2016;64:197-202.

25. Wang B, He D, Wang M, et al. Analysis of sternal healing after median sternotomy in low risk patients at midterm follow-up: retrospective cohort study from two centres. J Cardiothorac Surg 2019;14:193.

26. Matsusue Y, Yamamuro T, Oka M, et al. In vitro and in vivo studies on bioabsorbable ultra-highstrength poly(L-lactide) rods. J Biomed Mater Res 1992;26:1553-67.

27. Hautalahti J, Rinta-Kiikka I, Tarkka M, et al. Symptoms of Sternal Nonunion Late after Cardiac Surgery. Thorac Cardiovasc Surg 2017;65:325-31.

Cite this article as: Takahara S, Sasaki K, Saito T, Sakuma K, Fujiwara H, Yoshioka I, Kumagai K, Sun W, Takase K, Saiki Y. Clinical assessment of efficacy of poly-L-lactide sternal pin on sternal stability and post-operative pain: a prospective randomized trial in cardiovascular surgery. $\mathrm{J}$ Thorac Dis 2022;14(1):76-89. doi: 10.21037/jtd-21-1340 